\title{
Awareness and Willingness to Pay for Health Insurance: A Study of Darjeeling District
}

\author{
Maumita Ghosh ${ }^{1}$ \\ ${ }^{1}$ Department of Economics, Southfield College (formerly Loreto College), Darjeeling, India
}

\begin{abstract}
The present study is an effort to find out the response of the people of Darjeeling in the area of health insurance. As firstly, this study examines the respondents who are aware or not aware about health insurance as well as various sources of awareness; secondly, those who are aware have subscribed for it or not; thirdly, those who have not subscribed what are the reasons behind the same; and lastly are they willing to join and pay for it? If yes then what would be the possible amount? The study was conducted in some selected villages in Darjeeling district and 200 questionnaires were got filled from randomly selected general people. The results shown low level of awareness and willingness to join and pay for health insurance scheme.
\end{abstract}

Key words: health insurance, willingness to pay, bidding, canonical correlation, regression analysis.

\section{Introduction}

Of all the risks faced by the households, health risks pose the greatest threat to lives and livelihoods. The uncertainty of the timings of illness, its huge treatment costs make financial provision difficult for households (Tenkorang, 2001). Rapid increase in medical expenditure combined with the family's consumption expenditure has caused people to rethink about financing of their health care systems. Health insurance gives the opportunity to the people to finance their medical care so that they can alleviate some of their financial pressure. Health insurance actually gives partial reimbursement to the people for expenditure on selected diseases.

Although it is needless to say health insurance is an important mechanism in the modern world to save the individuals from the huge health shock, a very high percentage of people in West Bengal even from educated higher income groups are not covered under any health insurance policy and at the same time, although health care has become almost unaffordable for the poor people, it is surprising that the health insurance sector has not made much headway in India. Ahuja and De (2004) confirmed that the demand for health insurance is limited where supplies of health services is weak and explained interstate variation in demand for health insurance by poor in relation to variation in healthcare infrastructure. Till date the awareness level regarding health insurance is very poor in general masses. The present study is an effort to assess the individuals' awareness level and willingness to join and pay for the health insurance scheme in Darjeeling district of West Bengal and what are those factors on which the demand for health insurance depends. Therefore, we have the following objectives in mind,

\section{Objectives of the Study}

$>$ To add knowledge on the maximal WTP among rural and semi urban people in Darjeeling district of West Bengal,

$>$ To determine the socio-economic factors of willingness to join and pay for health insurance by non health insurance holders.

$>$ To find out the awareness level of the people and source of awareness of health insurance.

It was intended to give true representation of four blocks, viz., of Siliguri subdivision of the district where one block located in the hilly terrain. Selection of sample of respondents is made by following purposive random sampling and on the whole a sample size of 200 households (HH) is considered. In view of the fact that in the present study general public has been considered as unit of investigation, a sample framework consisting of equal number of respondents from each of the blocks has been constructed. The survey questionnaire included data of Household demographics, education, income, medical and non medical expenditure, savings, and any other kind of insurance like LIC and also self-reported illness episodes in the Household (HH) within the last 2 years prior to the interview. In our HH survey, the question on income referred to all sources of income, both cash and kind. It is also accepted in the literature that income might be prone to seasonal fluctuations and other "noises" due to in-kind income; these could possibly create a reporting-error or recall-bias but - according to Friedman it is assumed that households smooth their expenditure over time. Data of income lost and loan taken due to illness are also taken. Sampling followed a cross sectional design in a two-stage sampling method: in the first stage, we selected locations purposely, a mix of hilly region and plain areas. In the second stage, several 
villages (or semi-urban areas) within each block were randomly included, and at each block about $50 \mathrm{HHs}$ were surveyed.

\section{The Bidding Game}

Different HHs were given only one versions of the benefit package, which includes Hospitalization, expenses incurred for medical or surgical treatment for illness/disease and injury and reimbursement of costs for prescribed drugs and cost of general practitioners. The total value of which would be up to Rs. 10,000 per year and per person. After describing the benefit package the respondents were explained the essentials of insurance notably that it entails a prepayment of premiums according to certain age group in order to be eligible for the above said benefit package. At the same time those premiums are not re-paid when no claims are paid. The purpose of the explanation is to make them understand the difference between any other saving product and health insurance which might elicit a different level of Willingness to pay (WTP). After this the respondents were engaged in the 'bidding game' to establish WTP. Bidding game is the process where the respondent is presented with a price, which is increased by each time when the respondent accepts the bid, and lowered each time when the respondent rejects the bid. A bid was randomly assigned to the respondents started from Rs.120, Rs.150, Rs.220, Rs.250, Rs.350, Rs.450, and Rs.500 depending on their monthly income.

From the literature review it is found that some scholars are skeptical about the effectiveness of bidding game as it suffers from the interviewer's bias which they denoted as 'warm glow' problem (Van Exel et. al., 2006). The bias would exist when respondents accept an amount closer to the opening bid than they would actually do in reality. In our case, we compared the reported WTP values with the opening bids and found that the reported values were almost $15 \%$ to $20 \%$ different from the opening bids. So it is expected that our bidding game was free from warm glow problem.

The analysis of collected data has been carried out by using frequency distribution and percentages for multiple responses. Beside this the multiple regression and canonical correlation analysis have been made to draw meaningful inference from the study.

\section{Empirical Results}

In the survey face to face discussion was carried out with the head of the households and we found that a significant proportion of the sampled households are headed by male members in the family. (Table: 1) Majority of the respondents belonged to the age groups of $25-<35$ years followed by $35-<45$ and were married and living in nuclear families. Maximum respondents were primary educated and $4.5 \%$ respondents were found illiterate. Since Tea is the predominant industry in the surveyed region, $32.5 \%$ of the surveyed $\mathrm{HH}$ constituted tea garden labourers with some doing tea garden official job. We observed an employment category 'driver' who are associated (though in unorganized way) with the tourism industry. As far as level of income is concerned a major percentage of the respondents were having annual income less than Rs. 50,000. 56\% respondents have monthly income less than Rs.3000 and only $4.5 \%$ have monthly income level as high as Rs. 12000 to 15000 .

Table: 1 Socio-economic Profiles of the Respondents in Darjeeling

\begin{tabular}{|c|c|c|c|}
\hline Gender & No & $\%$ & \\
\hline Male & 187 & $93.50 \%$ & \\
\hline Female & 13 & $6.50 \%$ & \\
\hline Total & 200 & 100 & \\
\hline Marital status & No & $\%$ & \\
\hline Unmarried & 40 & 20 & \\
\hline Married & 160 & 80 & \\
\hline Age & No & Insured & Uninsured \\
\hline $18-<25$ & 19 & 2 & 17 \\
\hline $25-<35$ & 99 & 15 & 84 \\
\hline $35-<45$ & 62 & 15 & 47 \\
\hline $45-<55$ & 17 & 4 & 13 \\
\hline $55-<60$ & 3 & 1 & 2 \\
\hline
\end{tabular}


Awareness and Willingness to Pay for Health Insurance: A Study of Darjeeling District

\begin{tabular}{|c|c|c|c|}
\hline Total & 200 & 37 & 163 \\
\hline$\%$ & & $18.5 \%$ & $81.5 \%$ \\
\hline Type of Family & No & $\%$ & \\
\hline Joint & 63 & $31.50 \%$ & \\
\hline Nuclear & 137 & $68.50 \%$ & \\
\hline Total & 200 & 100 & \\
\hline Education & No & $\%$ & \\
\hline Illiterate & 9 & $4.50 \%$ & \\
\hline Primary and can write name & 112 & $56 \%$ & \\
\hline Secondary & 25 & $12.50 \%$ & \\
\hline $10^{\text {th }}$ & 13 & $6.50 \%$ & \\
\hline $12^{\text {th }}$ & 31 & $15.50 \%$ & \\
\hline Others & 10 & $5.00 \%$ & \\
\hline Total & 200 & $100 \%$ & \\
\hline Occupation & No & $\%$ & \\
\hline Service & 22 & 11 & \\
\hline Business & 12 & 6 & \\
\hline Tea Garden Labour & 65 & 32.5 & \\
\hline Shop & 21 & 10.5 & \\
\hline Driver & 19 & 9.5 & \\
\hline Daily Labour/Worker & 40 & 20 & \\
\hline Self Employed & 21 & 10.5 & \\
\hline Total & 200 & $100 \%$ & \\
\hline Income Per Month & No & $\%$ & \\
\hline Upto 3000 & 102 & $56 \%$ & \\
\hline $3000-<6000$ & 47 & $23.50 \%$ & \\
\hline $6000-<9000$ & 24 & $12 \%$ & \\
\hline $9000-<12000$ & 18 & $9 \%$ & \\
\hline $12000-<15000$ & 9 & $4.50 \%$ & \\
\hline
\end{tabular}

Source: field survey

The following table provides the summary statistics of the data collected.

Table: 2 Summary Statistics

\begin{tabular}{|l|c|c|c|c|c|}
\hline & IN & EDU & AGE & MED & EXP \\
\hline MEAN & 4408.00 & 4.920000 & 33.19000 & 479.1500 & 3269.500 \\
\hline MEDIAN & 2850.00 & 4.000000 & 32.00000 & 475.0000 & 2250.00 \\
\hline MAX & 15000.00 & 12.00000 & 55.00000 & 2000.000 & 10000.00 \\
\hline MIN & 1500.00 & 0.000000 & 20.00000 & 100.0000 & 1500.00 \\
\hline ST. DEV & 2968.907 & 3.811329 & 7.604805 & 288.8024 & 1850.579 \\
\hline
\end{tabular}

Source: Derived on the basis of data collected through field survey 
On an average the respondents are 33 years old, income per head is Rs. 4408 per month, non health expenditure per HH is RS.3269.50, mostly they are primary educated and per month medical expenditure is Rs. 479.

Table: 3 Awareness Level and Source of Awareness for Health Insurance

Source: field survey

\begin{tabular}{|l|l|l|}
\hline \multicolumn{2}{|l|}{ Awareness about Health Insurance } \\
\hline \multicolumn{1}{|l|}{} & No. & $\%$ \\
\hline not aware & 131 & 65.5 \\
\hline aware but do not subscribe & 32 & 16 \\
\hline aware and subscribed & 37 & 18.5 \\
\hline Source of awareness & \\
\hline TV and news paper & 16 & $24 \%$ \\
\hline friends and family & 18 & $26 \%$ \\
\hline agent and tax consultant & 30 & $43 \%$ \\
\hline Doctor & 5 & $7 \%$ \\
\hline Total & 69 & 100 \\
\hline
\end{tabular}

Out of the surveyed mass only $18.5 \%$ are insured to any health insurance scheme and $81.5 \%$ are uninsured. It is found that the mean willingness to pay for the insured person is higher than the mean willingness to pay for the uninsured person.

\subsection{Willingness to Pay of the Respondents}

$45 \%$ people said that they could subscribe Rs. $150-200$ as yearly premium for the proposed health insurance scheme and $29 \%$ were willing to pay as much as Rs $200-250$. Only $1.5 \%$ expressed their willing to pay as high as Rs 450-500. $4 \%$ respondents did not want to pay for any health insurance scheme. We assigned value 0 as their WTP. Only $4 \%$ respondents wanted to pay more than $1 \%$ of their income as health insurance premium. We have not considered respondents who are less than 18 years and more than 60 years old.

Table: 3 Willingness to Pay in Darjeeling

\begin{tabular}{|l|l|l|}
\hline WTP & $\begin{array}{l}\text { No } \\
\text { Respondents } \\
(\mathbf{2})\end{array}$ & $\begin{array}{l}\text { Of } \\
\text { Respondents } \\
(\mathbf{3})\end{array}$ \\
\hline $0-100$ & 8 & 4 \\
\hline $100-150$ & 19 & 9.5 \\
\hline $150-200$ & 90 & 45 \\
\hline $200-250$ & 58 & 29 \\
\hline $250-300$ & 4 & 2 \\
\hline $300-350$ & 0 & 0 \\
\hline $350-400$ & 17 & 8.5 \\
\hline $400-450$ & 0 & 0 \\
\hline $450-500$ & 3 & 1.5 \\
\hline
\end{tabular}

Source: Field survey

\section{Analysis Of Data}

\subsection{Multivariate Analysis of Willingness to Pay}

We analyze the data using linear multiple regression on the households' willingness to pay, by applying a standard model of the following form

$\mathrm{WTP}=\alpha+\beta_{1} \mathbf{X}_{1}+\beta_{2} \mathbf{X}_{2}+\cdots+\beta_{\mathrm{n}} \mathbf{X}_{\mathrm{n}}$

In which $\alpha$ represents the intercept (constant), and $\beta$ s the coefficients of the explanatory variables X. The WTP values that were obtained through the bidding game were subjected to multivariate analysis. The results are presented in Table 6. The table contains information about the significance of the impact of the different variables on WTP. The coefficient of variables ie, $\beta$ s show the strength of the influence of the independent variables on the dependent variable.

As the data base we have used the data of those $81.5 \%$ respondents who do not contribute to any health insurance scheme. The explanatory variables are marital status, education level, income per month, average medical expenditure per month, illness in the last 2 years for what the respondent had to be confined to bed in a 
hospital and loan taken due to illness or accident. The following linear regression model has been constructed and tested. The model is dummy variable regression model as for marital status there are two dummy variables, if married then we put ' 1 ' and if unmarried then ' 0 '. For illness episode also, if ill or met accident in the last 2 years then we put ' 1 ' and ' 0 ' otherwise. Therefore, the model can be specified in the following form

\section{$W T P=\alpha+\beta_{1} X_{1}+\beta_{2} X_{2}+\beta_{3} X_{3}+\beta_{4} X_{4}+\beta_{5} X_{5}+\beta_{6} X_{6}$}

Where, $X_{1}$ stands for marital status (MS), $X_{2}$ for education level (ED), $X_{3}$ for income per month (IN), $\mathrm{X}_{4}$ for medical expenditure per month (ME), $\mathrm{X}_{5}$ for hospitalization due to illness in the last 2 years (ILL) and $\mathrm{X}_{6}$ for loan taken due to illness (LN).

We have the following hypothesis regarding the relation between explanatory variables and dependent variable WTP.

\subsubsection{Hypotheses}

Hypothesis 1: There is no significant association between marital status and willingness to pay.

Hypothesis 2: There is no significant association between the education level and WTP.

Hypothesis 3: There is no significant association between income per month and WTP.

Hypothesis 4: There is no significant association between per month average medical expenditure of respondents and WTP.

Hypothesis 5: There is no significant association between illness or accident of respondents and their WTP.

Hypothesis 6: There is no significant association between loan taken due to illness and WTP value.

Table: 6 Result of Multivariate Regression Analysis:

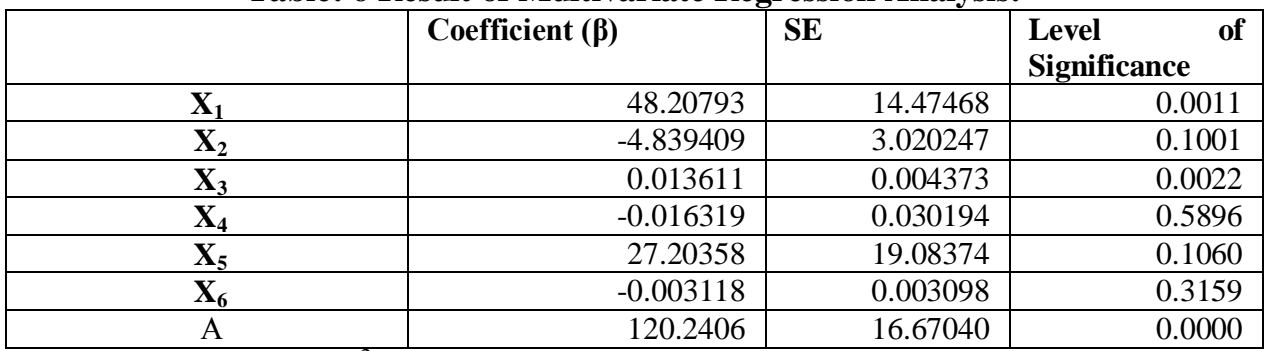

F-stat: 4.92155 , level of sig: $0.00, \mathrm{R}^{2}: 0.159$

The analysis of non health insurance policy holders has been made in order to know about their willingness to join and pay for health insurance. In the study we found $80 \%$ respondents are married and most of them have come from 25-34 years of age group. It is a socially accepted fact that irrespective of income level married people are more likely to be protective regarding their own life along with their spouse and children's' life. So they would like to pay for some health insurance scheme than the unmarried counterpart. Our regression result also supports this and hence we reject the null hypothesis 1 and accept that there is a positive relation between marital status and WTP value.

Analyzing data we found that more educated people are less likely to be willing to pay higher amount in a health insurance scheme. Highly educated respondents are often high income earners and at the same time their awareness level regarding other sorts of saving is high than their uneducated counterpart. So they want to invest a limited amount of money in health insurance schemes which will protect them from a sudden health attack and would invest more in other modes of savings which in turn give them high return. This is also significantly established in the regression result. So hypothesis 2 is not true and $\boldsymbol{\beta}_{2}<0$.

The relation between income and WTP is positive rejecting the null hypothesis. This is also proved in the correlation result. There we found that effect of education on WTP is secondary than the income. That means for the people income has a positively correlative relation with desire to invest in any health insurance scheme. So we found $\boldsymbol{\beta}_{3}>0$.

The possible effect of a recent experience of a health-related high-cost event on WTP was done by using information about incidence of hospitalizations in the past 2 years. The multivariate analysis (Table: 6) confirms that respondents who experienced a hospitalization in the last 2 years due to illness/accident were willing to pay more. So the hypothesis 5 is not true and $\boldsymbol{\beta}_{5}>0$.

Per month average medical expenditure and loan taken due to illness are two factors that may also influence the households to pay for a health insurance scheme. The first factor depends on the household size and age group of the $\mathrm{HH}$. Higher $\mathrm{HH}$ size and presence of children and elderly people lead to higher per month medical expenditure, which may influence the respondent for a higher level of WTP value. The regression result does not support this and which is true in the sense that health insurance schemes do not pay for this day to day medical expenditure. So per month medical expenditure does not come in the decision making behavior of the $\mathrm{HH}$ when he reveals his willingness to pay for a health insurance scheme. Therefore, hypothesis 4 is true. Poor people due to their less income and saving could not pay for the high cost of hospitalization and surgery which 
pose the greatest financial risk for them. This financial risk may influence them to take the decision of buying health insurance which in turn may end up into a higher value of WTP. But we have not found any significant positive relation between loan taken behaviour and WTP value. The value of $\boldsymbol{\beta}_{6}<0$ and insignificant. The result of the multivariate regression analysis is satisfactory in spite of the low value of $\mathrm{R}^{2}$. Pindyke and Rubinfield (1998) argued that where cross section data are involved, a lower value of $R^{2}$ may result because of wide variety in cross section data.

\subsection{Canonical Correlation Analysis (CCA)}

Canonical correlation is a multivariate statistical technique that studies the relation among two sets of variables where each set can be given some theoretical meaning in the sense of dependent and independent variables. In our case of willingness to pay to the health insurance canonical correlation analysis would be of great help to study the relation between the two set of variables namely hazards of illness and financial status and ability to pay to the health insurance. In doing so it would be possible to avoid separate regression for each of the dependent variables what we did in the previous sub section. Canonical variable is a linear combination of a set of original variables. Let us consider the first set of variables composed of medical expenditure, loan taken due to illness/hospital cost, income lost due to illness/confinement into bed and employment days lost all of which are indicative of hazards of illness and the second set of variables consisting of WTP, income, saving indicating financial status and ability to pay health insurance.

Set: 1 Hazards of illness: medical expenditure $\left(\mathrm{X}_{1}\right)$, loan taken due to illness/hospital cost $\left(\mathrm{X}_{2}\right)$, income lost due to illness/confinement into bed $\left(\mathrm{X}_{3}\right)$, employment days lost $\left(\mathrm{X}_{4}\right)$.

Set: 2 Financial Status and ability to pay to health insurance: WTP $\left(Z_{1}\right)$, income $\left(Z_{2}\right)$, Saving $\left(Z_{3}\right)$.

It is to be noted that CCA focuses on accounting for the maximum amount of the relationship between two sets of variables, rather than within a simple set. The result is that first pair of canonical variates is derived so as to have the highest interrelation possible between two sets of variables. Second pair of canonical variates are derived so that is exhibits the maximum relationship between two sets of variables not accounted for by the first pair of variates and so on. Maximum number of canonical variables equals the number of variables from the smallest variable set.

The results of calculation of canonical correlation have been shown below.

Table: 7 Eigen Values:

\begin{tabular}{llrr}
\hline & F1 & F2 & \multicolumn{1}{c}{ F3 } \\
\hline $\begin{array}{l}\text { Eigen value } \\
\text { Variability }\end{array}$ & 0.208 & 0.001 & 0.001 \\
$(\%)$ & 98.977 & 0.683 & 0.340 \\
Cumulative \% & 98.977 & 99.660 & 100.000 \\
\hline
\end{tabular}

The eigen values are approximately equal to the Cannonical correlation squared.

Table: 8 Canonical Correlations:

\begin{tabular}{lll}
\hline F1 & F2 & F3 \\
\hline 0.456 & 0.038 & 0.027 \\
\hline
\end{tabular}

Table: 9 Wilks'

Lambda test:

\begin{tabular}{ccrrr}
\hline Lambda & F & DF1 & \multicolumn{1}{c}{ DF2 } & \multicolumn{1}{c}{ Pr $>$ F } \\
\hline 0.790 & 3.965 & 12 & 510.9215 & $<0.0001$ \\
0.998 & 0.070 & 6 & 388 & 0.999 \\
0.999 & & & & \\
\hline
\end{tabular}


Wilks' Lamda test is carried out to test the significance of Cannonical Correlation Coefficient. It implies that the first measure of Canonical Correlation is 0.456 is significant at $1 \%$ level while the other two are not. The $F_{1}$ value is reflective of the fact that $2^{\text {nd }}$ set of variables representing the financial status and ability of the individuals has adequate association with the hazards of illness.

\section{Conclusion}

Although health insurance is not a new concept and with the time more and more people are getting aware about it, but this awareness has not reach to that extent that people subscribe for it. As a result it was found from this study that just $18.5 \%$ are being covered by some form of health insurance and large portion of the population is still financing health care expenditure out of pocket. Various socio- economic variables like marital status, education, income level, occupation etc drives people of Darjeeling to take the decision of taking health insurance. Since Darjeeling is mostly dependent on tea and tourism, we found a category of labour that is named as 'tea garden labour' who works in different tea gardens. Tea garden job is a job in organized sector where the garden owners are supposed to arrange some basic health facilities for its workers. According to secondary data there are 16 health centres in the tea garden areas of Naxalbari block. These labourers, we found, are mostly reluctant to subscribe for health insurance schemes as they have a basic facilities of health given by their employer. Besides this the association between various variables linked with the respondents has been determined with their willingness to pay for health insurance and the results found that on the one hand significant association exist between the marital status, income of respondents, hospitalization due to illness/ accident with their willingness to pay for health insurance. On the other hand no such association is found in case of monthly medical expenditure and loan taken due to illness. Regarding education the result shown that educated people are reluctant to invest more in health insurance rather they prefer to invest more in other modes of savings which in turn give them high return. At the same time analysis of Canonical correlation gives us the idea that financial status and ability of the individuals has adequate association with the hazards of illness as a whole.

\section{References:}

[1]. Ahuja, R. and De, I. (2004) "Health Insurance for the Poor Need to Strengthen Healthcare Provision" Economic and Political Weekly, Vol. 39, No. 41, pp. 4491-4493.

[2]. Archin-Tenkorang, Dyna(2001). Health insurance for the informal sector in Africa: Design features, risk protection, and resource mobilization. CMH Working paper series, paper no WG3:1. Washington DC. (www.cmhealth.org/docs/wg3_paper 1.pdf)

[3]. Dror, M.D. (2006) "Health Insurance for the Poor: Myths and Realities" Economic and Political Weekly, Vol. 41, No. 43 \& 44, pp. 4541-4544.

[4]. Exel van NJA, Brouwer WBF, van den Berg B, Koopmans chap MA (2006). 'With a little help from an anchor: Discussion and evidence of anchoring effects in contingent valuation'. Journal of Socio-Economic 2006; 35(5):836-53

[5]. Health on the March 2010. Published by west Bengal Health Department. Sasthya Bhavan. Kolkata.

[6]. www.healthinsuranceindia.org 